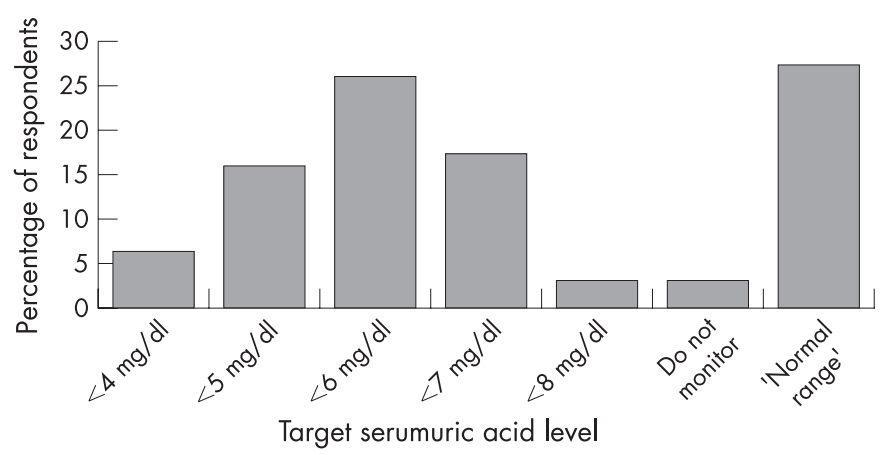

Figure 1 Discordance between doctors concerning the level of serumuric acid that is thought to inflect aduquete controlf of gout.

within 2 weeks. Sixteen per cent of respondents would treat asymptomatic hyperuricaemia with ULT, with a marked difference in practice being observed between rheumatologists and internal medicine specialists (15\% versus 59\%, respectively). Importantly, opinions varied considerably on what sUA level might be regarded as representing adequate control in a gout patient (fig 1).

It is interesting to consider some of these findings in light of the recent EULAR recommendations. These make clear, for example, that sUA levels do not confirm or exclude a diagnosis of gout. Despite this, nearly all respondents (97\%) stated that they would rely on measuring sUA for precisely that purpose. For gout management the recommendations assign a central role to sUA and define the therapeutic goal of ULT as being to promote crystal dissolution, prevent crystal formation and improve clinical symptoms by maintaining sUA below $6 \mathrm{mg} / \mathrm{dl}$. The survey findings show, however, that most physicians perceive a reduction in the frequency of acute attacks as the central goal of therapy and that the ability to cure the condition by maintaining sUA below $6 \mathrm{mg} / \mathrm{dl}$ is not yet universally appreciated.
A caveat of any such survey is that physicians may have responded on the basis of what they know should be done rather than what they actually do in practice. They may also have completed the survey in haste and possibly misinterpreted some of the questions. Nevertheless, a large number of practitioners representing several countries in Europe participated in this simple survey.

The authors hope that, as awareness of the EULAR recommendations grows, and the goal of maintaining sUA below $6 \mathrm{mg} / \mathrm{dl}$ becomes more widely recognised, all patients with gout will be spared the burden of this eminently treatable condition.

\section{Authors' affiliations \\ M Doherty, Academic Rheumatology, Clinical Sciences Building, University of Nottingham, City Hospital, Nottingham, UK \\ T Bardin, Fédération de Rhumatologie Hôpital Lariboisière, Paris, France \\ E Pascual, Hospital General Universitario de Alicante, Alicante, Spain}

Funding: The study was financed by Ipsen, France, for which the authors are grateful.

Correspondence to: Professor M Doherty, Academic Rheumatology,

Clinical Sciences Building, University of Nottingham, City Hospital,

Hucknall Road, Nottingham NG5 1PB, UK; michael.doherty@nottingham. ac.uk

Accepted 25 April 2007

\section{REFERENCES}

1 Zhang W, Doherty M, Pascual E, et al. EULAR evidence based recommendations for gout. Part I: diagnosis. Report of a task force of the EULAR Standing Committee for International Clinical Studies Including Therapeutics (ESCISIT). Ann Rheum Dis 2006;65:1301-11.

2 Zhang W, Doherty $M$, Bardin T, et al. EULAR evidence based recommendations for gout. Part II: management. Report of a task force of the EULAR Standing Committee for International Clinical Studies Including Therapeutics (ESCISIT). Ann Rheum Dis 2006;65:1312-24.

\title{
Like father, like son
}

\section{Jeffrey Lee, Peter Merry, Richard Ball, Karl Gaffney}

W e present a unique case of familial primary Sjogren's syndrome (pSS) involving a father and son that challenge several key features of this disease onset.

A 20-year-old man (fig 1) was referred with a 4-year history of recurrent parotitis and persistent bilateral parotid swelling. He also had increasing fatigue and night sweats for 3 months and cosmetically unacceptable parotid swellings. Although Schirmer's test was normal, he was found to have positive Ro, La and antinuclear antibodies. Computerised tomography scans of his abdomen and chest showed no abnormality. Subsequent parotid biopsy showed a low-grade mucosaassociated lymphatic tissue (MALT) lymphoma. A diagnosis of pSS that was complicated by MALT lymphoma was made. The parotid swellings were reduced by $50 \%$ with no further fatigue or night sweats after the introduction of prednisolone $30 \mathrm{mg}$ once daily and hydroxychloroquine.

On subsequent inquiry, his 55-year-old father was found to have had a 15-year history of bilateral parotid swellings for which he never sought medical attention (fig 2). He was a mechanical engineer who gave a 15 -year history of dry eyes and mouth and recurrent cervical lymphadenopathy. His Schirmer's test was strongly positive, with measurements of $2 \mathrm{~mm}$ in his left eye and $0 \mathrm{~mm}$ in his right. He also had positive Ro and La antibodies along with hypergammaglobulinaemia (immunoglobulin (Ig)G 25.2 (4.9-16.1) g/l, IgM 3.95 (0.60-2.1) g/l), lymphopenia (lymphocyte $\left.0.4 \times 10^{9}(1.1-3.5) / 1\right)$ and an erythrocyte sedimentation rate of $92(1-10) \mathrm{mm} / \mathrm{h}$. As he remained relatively asymptomatic apart from his ocular and oropharyngeal dryness, he was treated with artificial tears only.

This case report highlights several unusual features. Although familial clustering of different autoimmune diseases in individuals with pSS have been reported, familial cases of

Abbreviations: MALT, mucosa-associated lymphatic tissue; pSS, primary Sjogren's syndrome 


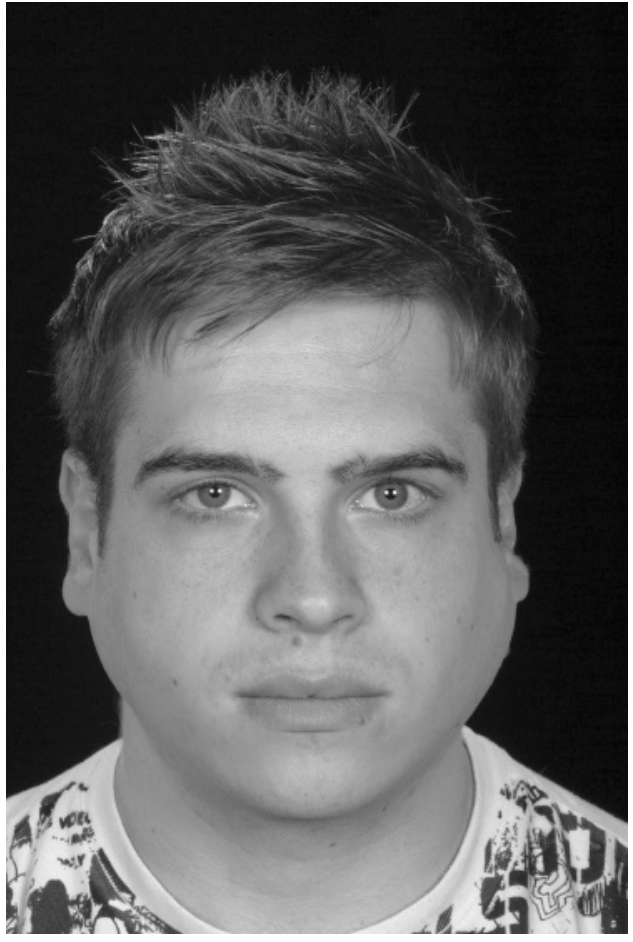

Figure 1 A 20-year-old man with recurrent parotitis and persistent bilateral swelling.

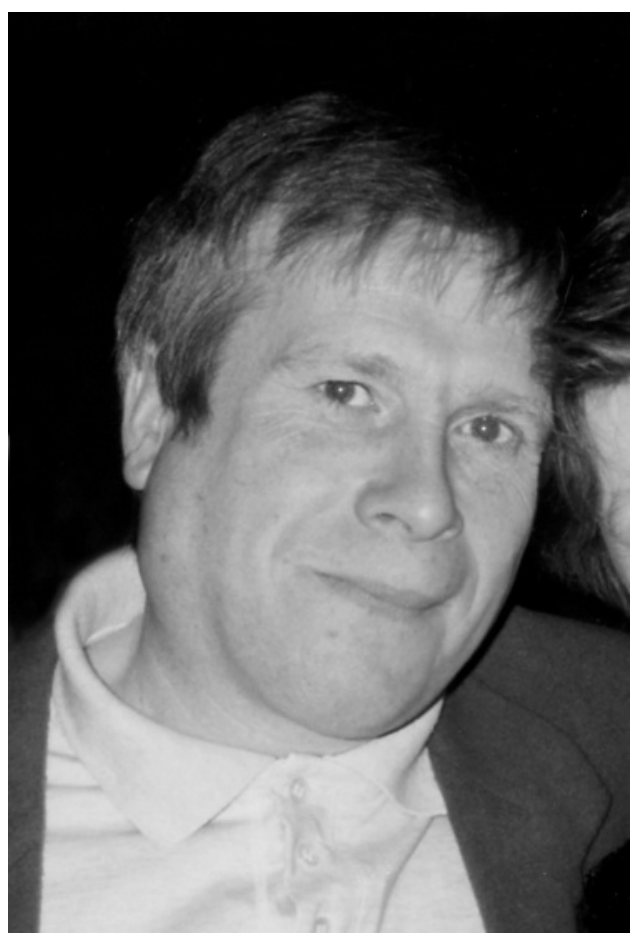

Figure 2 A 55-year-old man presented with bilateral parotid swelling.

pSS at any age are uncommon. ${ }^{1}$ A literature search shows no previous documented cases of familial pSS involving father and son. pSS has a peak incidence in the fourth and fifth decades of life, with a female:male ratio of $9: 1 .^{2}$ Both of our patients were male members and one patient presented with symptoms since his teenage years.
Table 1 Classification criteria as defined by the European Study Group on classification of Sjogren's Syndrome ${ }^{8}$ in index case and parent

\begin{tabular}{lll}
\hline Criteria & Index case & Parent \\
\hline Ocular symptoms & - & + \\
Oral symptoms & + & + \\
Positive Schirmer's test & - & + \\
Autoantibodies (to Ro and La) & + & + \\
\hline +, presence of criteria; - absence of criteria.
\end{tabular}

Although a genetic predisposition to pSS appears to exist, the level of genetic contribution is unknown. ${ }^{1}$ Family members with pSS seem to share similar phenotypes, with almost identical clinical presentation and serological data. ${ }^{3}$ In our case, the proband presented in the patient's early 20s with MALT lymphoma, whereas his father had lived with the symptoms of pSS undiagnosed (table 1). Lymphoma is usually a late complication of pSS, with a median time from pSS diagnosis to lymphoma diagnosis of 7.5 years. $^{56}$

Genetic studies of pSS already show strong associations with major histocompatibility complex genes, including HLA-DR3, which may also determine the severity of the autoimmune disease. ${ }^{7}$ Future studies comparing the clinical, serological and genetic features of familial pSS are needed to gain further understanding of this complex multifactorial disorder.

\section{ACKNOWLEDGEMENTS}

We are grateful to the rheumatology department for data collection.

\section{Authors' affiliations}

Jeffrey Lee, Peter Merry, Karl Gaffney, Department of Rheumatology,

Norfolk \& Norwich University Hospital, Norfolk, UK

Richard Ball, Department of Histopathology, Norfolk \& Norwich University Hospital, Norfolk, UK

Funding: None.

Competing interests: None.

Ethical approval: Informed consent was obtained from both patients for publication of their details.

Correspondence to: Dr J Lee, Department of Rheumatology, Norfolk \& Norwich University Hospital, Colney Lane, Norwich, Norfolk NR4 7UY, UK; jsaxx999@doctors.org.uk

\section{Accepted 19 July 2006}

\section{REFERENCES}

1 Bolstad Al, Jonsson R. Genetic aspects of Sjogren's syndrome. Arthritis Res 2002;4:353-9.

2 Jonsson R, Haga H-J, Gordon T. Sjogren's syndrome. In: Koopman WJ, eds. Arthritis and allied conditions: a textbook of rheumatology, 14th ed. Philadelphia: Lippincott, Williams \& Wilkins, 2001:1736-59.

3 Scofield RH, Kurien BT, Reichlin M. Immunologically restricted and inhibitory anti-RO/SSA in monozygotic twins. Lupus 1997;6:395-8.

4 Bolstad Al, Haga HJ, Wassmuth R, Jonsson R. Monozygotic twins with primary Sjogren's Syndrome. J Rheumatol 2000;27:2264-6.

5 Kassan SS, Thomas TL, Moutsoupoulos HM, Hoover R, Kimberley RP, Budman DR. Increased risk of lymphoma in sicca syndrome. Ann Intern Med 1978;89:888-92.

6 Voulgarelis M, Dafni UG, Isenberg DA, Moutsopoulos HM. Malignant lymphoma in primary Sjogren's syndrome. Arthritis Rheum 1999;42:1765-2.

7 Foster H, Stephenson A, Walker D, Cavanagh G, Kelly G, Griffiths I. Linkage studies of HLA and primary Sjogren's syndrome in multicase families. Arthritis Rheum 1993;36:473-84.

8 Vitali C, Bombardieri S, Moutsopoulos HM, et al. Preliminary classification criteria for Siögren's syndrome. Results of a prospective concerted action supported by the European Community. Arthritis Rheum 1993;36:340-7. 